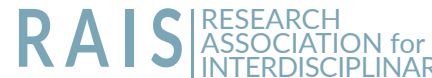 OCTOBER 2O17 STULDIES
}

\section{Morocco and ECOWAS A strategic adhesion with big potential for Moroccan SMEs}

\author{
Hamza El Guili \\ PhD Candidate, University Abdelmalek Essadi (UAE) \\ Tangier, Morocco \\ hamza.el.guili@gmail.com
}

\begin{abstract}
The SMEs (Small and Medium-sized enterprises) are an essential component of the world's economy. They represent more than $95 \%$ of the global existing companies and they largely contribute to the jobs creation inside many countries. In Morocco for example, the SMEs represent the large majority of active companies in the market (95\%) and contribute to $40 \%$ of private investments and to $30 \%$ of exportations.

The aim of this paper is to perform a systematic and recent literature review to determine the different theories of the internationalization of SMEs. The selected theories are treated from three major perspectives (traditional perspective, network perspective and emergent perspective).

In addition, this paper discusses the Moroccan recent politic of integration in Africa and the eventual adhesion of the country to the Economic Community of West African States (ECOWAS). This adhesion will offer more opportunities to the Moroccan SMEs in West Africa.

KEY WORDS: SMEs, Morocco, Internationalization process, ECOWAS.
\end{abstract}

\section{Introduction}

The SMEs (Small and Medium-sized enterprises) are an essential component of the world's economy. They represent more than $95 \%$ of the global existing companies and they largely contribute to the jobs creation inside the OECD countries. 
Small and Medium-sized Enterprises are responsible for creation of most jobs, products, tax revenues, welfare, and poverty alleviation in developing economies (Ahimbisibwe et al. 2016; Kandasaami 2004; Ntayi et al, 2011; Kwesiga 2006; Kasekende and Opondo 2003).

They provide the economy with a continuous supply of ideas, skills and innovations necessary to promote competition and the efficient allocation of scarce resources (Ahmed and Nwankwo 2013; Kasekende and Opondo 2003).

In Morocco, for example, SMEs are found in all sectors ranging from manufacturing, construction, services etc. They represent the large majority of active companies in the market (95\%) and contribute to $40 \%$ of private investments and to $30 \%$ of exportations. With the Moroccan recent politic of integration in Africa, under the reign of his Majesty the King Mohamed VI, and the country's return to the African Union after a 33-year absence, the country has made an official request to join the Economic Community of West African States (ECOWAS).

\section{LITERATURE REVIEW}

\section{The traditional perspective}

\subsection{Uppsala model}

In the Uppsala model, the internationalization process is facilitated by step-by-step decisions and following the acquisition of sufficient experience and realization of gains from domestic market (Johanson and Vahlne 1990, 23). Johanson and Vahlne (1990, 23) further argued that internationalization involves all the activities such as exploring possibilities to start exporting to a new country, set up own exporting channels, and start its own subsidiary.

The model is founded on four core concepts: market knowledge, market commitment, commitment decisions and current activities (Forsgren 2002). This model has incorporated results of previous empirical studies of the development of international operations, seeking theoretical explanation through the behavioral theory of the firm (Cyert and March 1963).

The Uppsala model analyzes the internationalization as a gradual learning process, and this model places the experience of the manager and the organization gradually as the key to internationalization (Johanson and Vahlne 1977). Furthermore, it 
integrates knowledge from this experience in foreign markets, the company supplies its decision process.

Figure 1. The Uppsala model of internationalization (Source Johanson \& Vahlne, 1977)

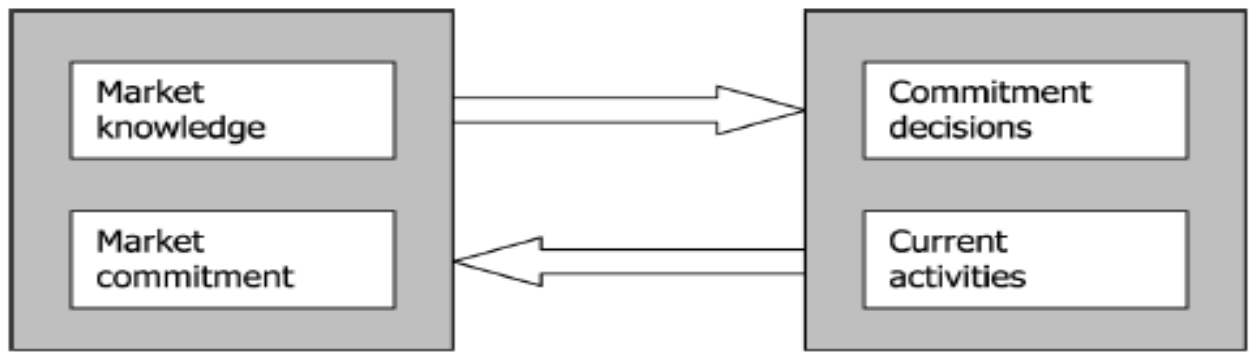

\subsection{The innovation-Related Internationalization Model (I-Model).}

The term "innovation-related" comes essentially from the work of Rogers (1962, cited in Gankema et al. 2000), in which each subsequent stage of internationalization is considered as an innovation for the firm (Gankema et al. 2000).

The focus of this model is exclusively on the export development process, in particular of small and medium-sized firms (Mitja Ruzzier, Robert D. Hisrich, and Bostjan Antoncic 2006). Leonidou and Katsikeas (1996) on the basis of a comprehensive review of the most important models (Bilkey and Tesar 1977; Cavusgil 1980; Reid 1981) concluded that the models are a number of fixed, sequential stages, although the number of stages varies considerably between models, ranging from as few as three to as many as six. They also identified three generic stages: the pre-export stage; the initial export stage, and the advanced export stage.

The first two types of models (the Uppsala and Innovation-related models) have been used to analyze small, but also large, firms with the focus on explaining the development of internationalization and international activities (Mitja Ruzzier, Robert D. Hisrich, and Bostjan Antoncic 2006).

Both the U-models and the I-models can properly be regarded as behaviorally oriented (Andersen 1993). Based on the arguments by the authors, the gradual pattern of the firm's internationalization process can mainly be attributed to two reasons. The first reason is the lack of knowledge by the firm, the second is the uncertainty associated with the decision to internationalize. 


\section{The network perspective}

A network approach, as it is developed by same Swedish researchers in industrial marketing and international business ( Hammarkvist, Håkansson \& Mattsson, 1982) is compared with the transaction cost approach associated with Oliver Williamson (Williamson 1975, 1979, 1981).

In the network perspective, Johanson and Mattsson $(1993,306)$ described internationalization as a cumulative process, in which relationships are continually established, maintained, developed, broken and dissolved in order to achieve the objectives of the firm".

This view, nevertheless, seems somewhat fragmented as it focuses exclusively on relationships (Mitja Ruzzier, Robert D. Hisrich, and Bostjan Antoncic 2006). Assuming that SMEs operate within their natural context, the view of Johanson and Vahlne (1990, 20) developed from Johanson and Mattsson (1993) appears more concise. They define internationalization as the "process of developing networks of business relationships in other countries through extension, penetration, and integration". According to Coviello \& Munro 1997; Coviello 2006; Musteen, Datta, \& Butts 2014; Musteen, Francis, \& Datta 2010, SMEs, unlike big firms, rely on their network relationships to internationalize. They found that the internationalization process of small software firms reflects an accelerated version of the stage model perspective, and is driven, facilitated, and inhibited by a set of formal and informal network relationships.

\section{Emergent perspective}

\subsection{The International Entrepreneurship Theory (IET) \& international new ventures (INV)}

International entrepreneurship is the study of cross-border entrepreneurial behavior focuses on how actors discover, enact, analyze and exploit opportunities in the creation of new goods or services (Masum \& Fernandez 2008). As defined by McDougall and Oviatt $(2000,903)$, international entrepreneurship (IE) is: " . . a combination of innovative, proactive and risk-seeking behavior that crosses national borders and is intended to create value in organizations... the study of IE includes research on such behavior and research comparing domestic entrepreneurial behavior in multiple countries."

Oviatt and McDougall $(1994,49)$ defined an INV as "a business organization that, from inception, seeks to derive significant competitive advantage from the use of resources and the 
sale of outputs in multiple countries". In other words, INVs' distinctive characteristic is that they internationalize, or at least intend to do so, from inception (Alain Verbeke, M. Amin Zargarzadeh, and Oleksiy Osiyevskyy 2014).

The INV concept has been widely praised as representing a useful challenge to the validity of prior paradigms addressing the process of internationalization, especially the Uppsala model (Autio 2005; Zahra 2005).

Figure 2. Types of International New Ventures (Oviatt and McDougall 1994)

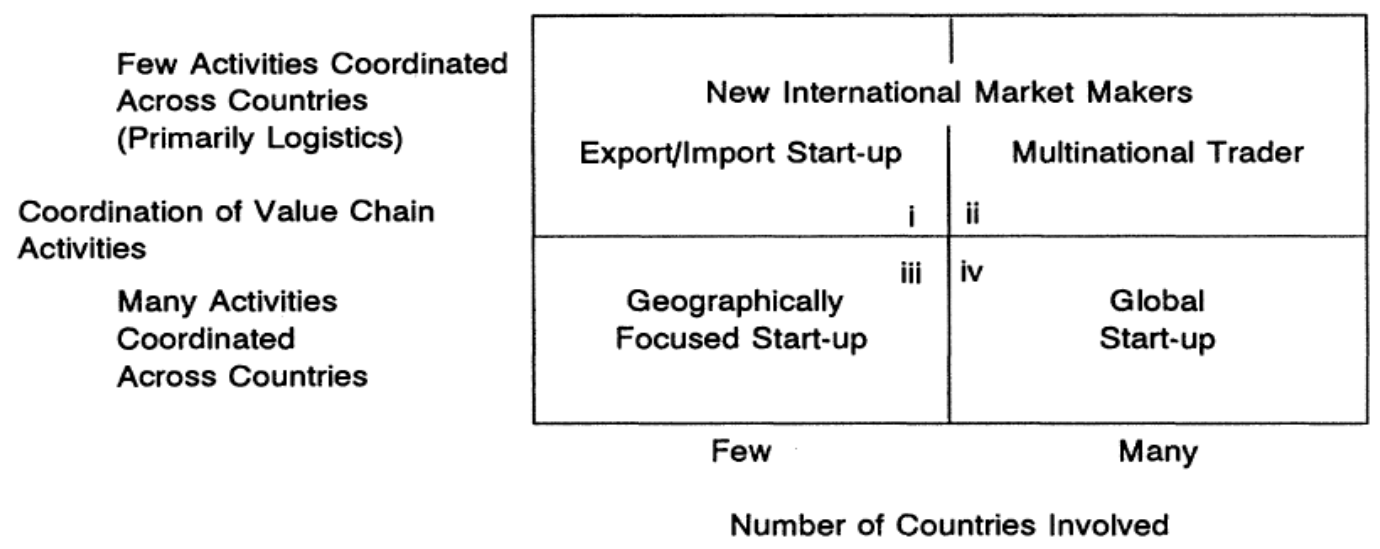

\section{Methodology and results}

Trade between Morocco and sub-Saharan Africa has been on an upward trend since 2009 , with an annual growth of $12.8 \%$ between 2000 and 2015 .

In addition, Morocco has concluded numerous agreements with sub-Saharan African countries in the form of trade and tariff agreements, based on the Most Favored Nation (MFN) clause, or multilateral agreements.

Based on statistics of the Moroccan Foreign Exchange Office in 2015, the Moroccan Foreign Direct Investment (FDI) in the Sub-Saharan Africa is increasing within the last years, which explains the Moroccan Foreign policy intention.

This confirmatory research was also based on other statistics of the Moroccan Foreign Exchange Office, the World Bank World Integrated Trade Solution (WITS) and the COMTRADE, which clearly analyses the trade between Morocco and Sub-Saharan African; Thus, we closely studied a survey conducted by Inforisk, to analyze the degree of internationalization of Moroccan SMEs. 
Figure 3. Evolution of the Moroccan FDI in Sub-Saharan Africa between 2003- 2015

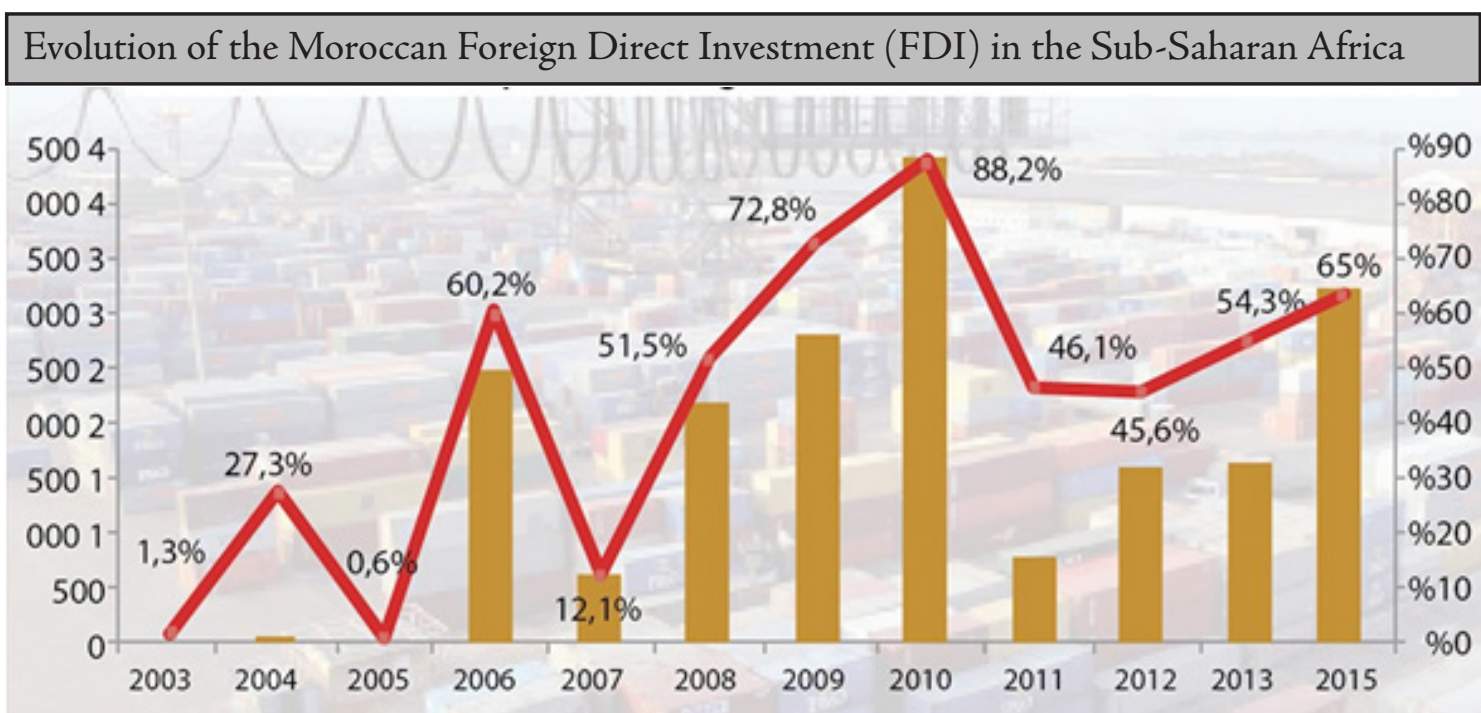

The flow of Moroccan FDI in the Sub-Saharan Africa in milions of dirham (left axis)

Part of Sub-Sahara Africa in the global Moroccan FDI (right axis)

Trade relations between Morocco and sub-Saharan Africa are asymmetrical as they tend to benefit Morocco more than the Sub-Saharan countries. In this context, it can be explained by its trade balance with the continent which has become a surplus since 2008 .

Figure 4. Trade exchange between Morocco and African countries (in billions of DH)

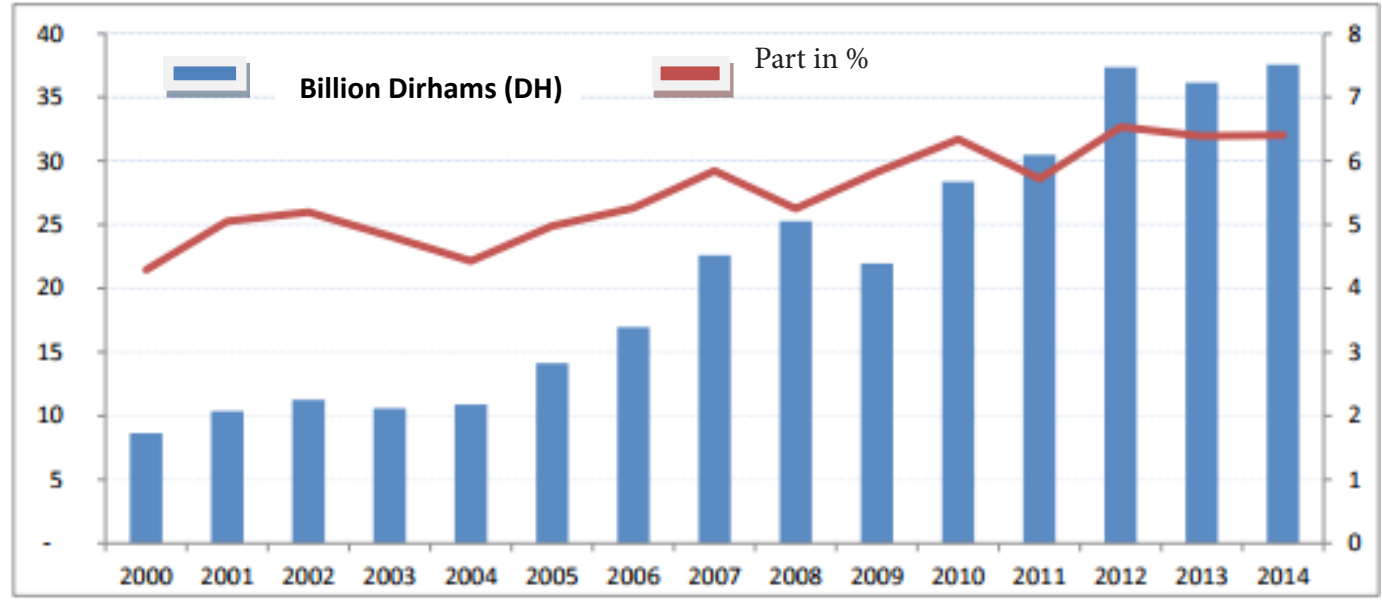


Figure 5. Destinations of the Moroccan FDI in Sub-Saharan Africa between 2011 and 2015

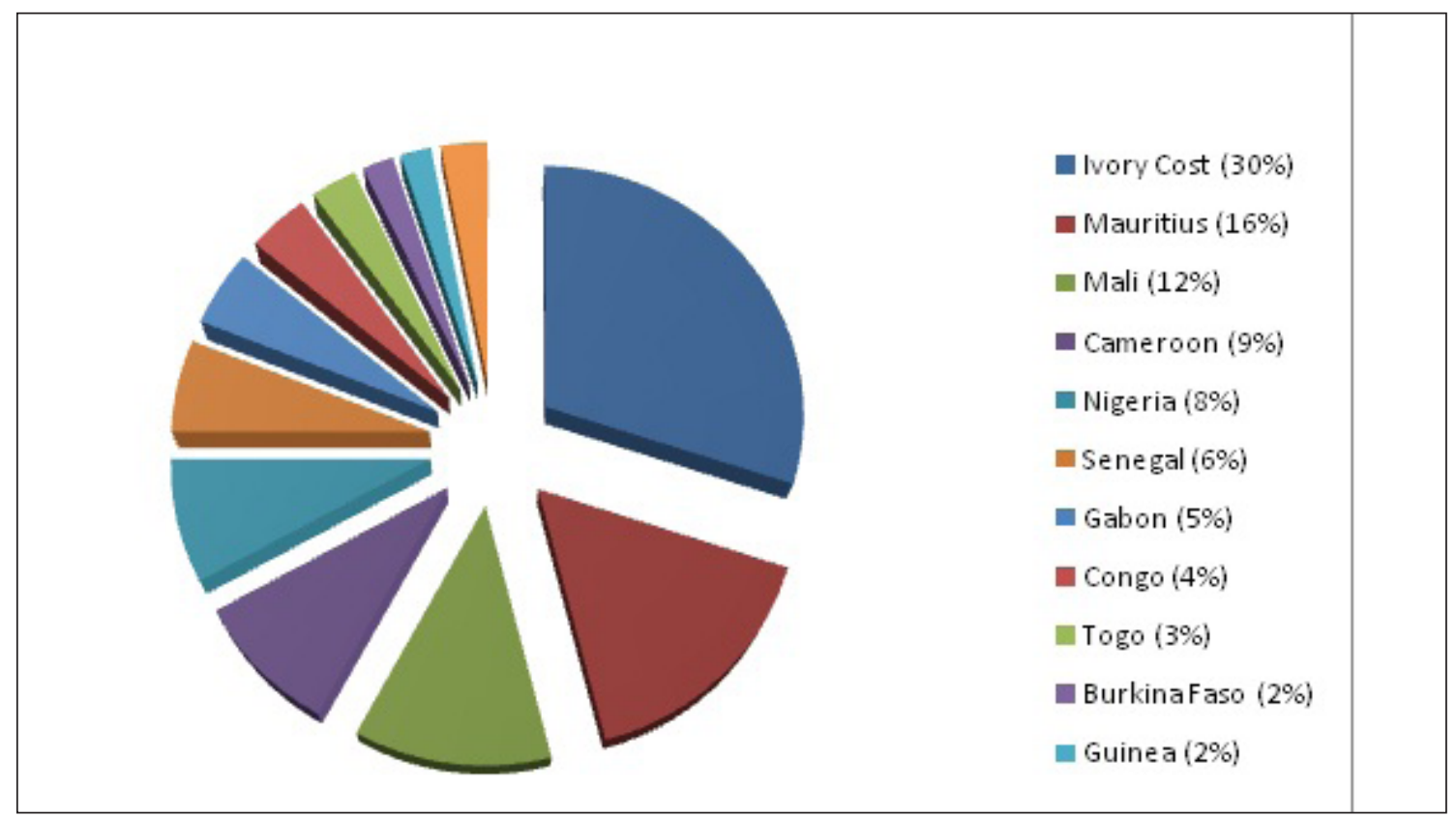

The acceleration of Moroccan FDI in sub-Saharan Africa can be explained by the relaxation of investment regulations. Moroccan companies beneficiated from two main measures:

The first (started in August 2014) is the liberalization of investment abroad of up to a maximum of 30 million DH per year for legal entities with at least three years of activity, provided that the company's accounts are certified by an external auditor and that the proposed investment directly relates to the entity's business activity. The second (started in December 201), is the increase in the transferable amount for investment abroad to a ceiling of MAD 100 million for Africa and MAD 50 million for other continents. Furthermore, a MAD 200 million fund has been created in order to strengthen the presence of private Moroccan operators in the African market. 


\section{Conclusion}

Morocco's foreign politic has been oriented to the African continent since 2000, due to a political and an economic willingness. According to a survey of InfoRisk, only $20 \%$ of Moroccan SMEs (which represents less than 1000 firms) are currently exporting to Africa, and only 150 of them are actively present in the continent. Yet, this category of firms represents a big potential.

There are many challenges facing the exporting SMEs, such as: the lack of information in some markets, political climate, regulatory constraints etc.

The presence of several institutions available for Moroccan entrepreneurs and Moroccan SMEs, interested to go to the international, such as, "Maroc Export", "AMDIE" and "ASMEX", constitutes a real value for the SMEs who wish to internationalize.

The eventual adhesion to the Economic Community of West African States (ECOWAS) will give a dynamic to the Moroccan SMEs, especially in the West region of Africa.

\section{References}

Alain Verbeke, M. Amin Zargarzadeh, and Oleksiy Osiyevskyy. 2014."Internalization Theory, Entrepreneurship and International New Ventures." Multinational Business Review 22 69-246 :(3). doi:10.1108/MBR0023-2014-06-.

Andersen, Otto.1993."On the Internationalization Process of Firms: A Critical Analysis.” Journal of International Business Studies 31-209:(2) 24. doi:10.1057/palgrave.jibs.8490230.

Directorate of Financial Studies and Forecast, "Moroccan-African relations: The ambition of new borders," 2014.

“Export: La Peur Pesante de l'inconnu." 2017. L'Economiste. July 15. http://www.leconomiste. com/article/1014966-export-la-peur-pesante-de-1-inconnu.

Forsgren, Mats, Ulf Holm, and Jan Johanson (eds.). 2015. Knowledge, Networks and Power: The Uppsala School of International Business. Palgrave Macmillan UK.

Gankema, Harold GJ, Henoch R. Snuif, and Peter S. Zwart. 2000. "The Internationalization Process of Small and Medium-Sized Enterprises: An Evaluation of Stage Theory." Journal of Small Business Management 15 :(4) 38.

Inc, Google. 2017."Relations between Morocco and Sub-Saharan Africa: What Is the Potential for Trade and Foreign Direct Investment?" OCP Policy Center. February 1. http://www. 
ocppc.ma/publications/relations-between-morocco-and-sub-saharan-africa-whatpotential-trade-and-foreign.

Johanson, Jan, and Lars-Gunnar Mattsson. 1987. "Interorganizational Relations in Industrial Systems: A Network Approach Compared with the Transaction-Cost Approach." International Studies of Management \& Organization 48-34:(1) 17.

McDougall, Patricia Phillips, and Benjamin M. Oviatt. 2000."International Entrepreneurship: The Intersection of Two Research Paths." Academy of Management Journal:(5) 43 906-902.Mitja Ruzzier, Robert D. Hisrich, and Bostjan Antoncic. 2006. "SME Internationalization Research: Past, Present, and Future." Journal of Small Business and Enterprise Development 97-476:(4) 13. doi:14626000610705705/10.1108.

Ngoma, Mohammed, Abaho Ernest, Sudi Nangoli, and Kusemererwa Christopher. 2017. "Internationalisation of SMEs: Does Entrepreneurial Orientation Matter?" World Journal of Entrepreneurship, Management and Sustainable Development 113-96:(2) 13. doi:10.1108/WJEMSD0039-2016-08-.

Oviatt, Benjamin M., and Patricia P. McDougall. 2005. "The Internationalization of Entrepreneurship." Journal of International Business Studies 8-2:(1) 36.

Oviatt, Benjamin M., and Patricia Phillips McDougall. 1994.“Toward a Theory of International New Ventures." Journal of International Business Studies, 45-64.

Tarek, Bel Hadj, Mighri Zouhayer, and Ghodbane Adel. 2017. "Entrepreneurial Competitive Intelligence Between Uppsala Model and Born Global Theories in the Case of North African SMEs." Journal of the Knowledge Economy, June, 1-22. doi:10.1007/ s13132-017-0489-6.

Zahra, S.A. 2005. "A theory of international new ventures: a decade of research", Journal of International Business Studies, 36 (1): 20-28. 